\title{
Study of nutritional status and its relation to morbid conditions among adolescent girls residing in social welfare hostels in the Kuppam mandal of Chittoor district, Andhra Pradesh, India
}

\author{
Sharvanan E. Udayar*, Deepthi Kommula, Devi Vara Prasad
}

\begin{abstract}
Department of Community Medicine, PES Institute of Medical Science and Research, Kuppam-517425, Chittoor District, A.P, India
\end{abstract}

Received: 23 December 2015

Revised: 23 January 2016

Accepted: 04 February 2016

\author{
*Correspondence: \\ Dr. Sharvanan E Udayar, \\ E-mail: saravananudayar83@gmail.com
}

Copyright: ( $)$ the author(s), publisher and licensee Medip Academy. This is an open-access article distributed under the terms of the Creative Commons Attribution Non-Commercial License, which permits unrestricted non-commercial use, distribution, and reproduction in any medium, provided the original work is properly cited.

\begin{abstract}
Background: Adolescence period is very crucial since these are the formative years in the life of an individual when major physical, psychological and behavioural changes take place. The aim and objective of study was conducted as part of Indian Council of Medical Research (ICMR), Short Term Studentship (STS) project and was done with the objectives of assessing the nutritional status and morbidity conditions among adolescent girls residing in a social welfare hostel and to study association between nutritional status and morbidity conditions among these adolescent girls.

Methods: A cross sectional study was conducted among adolescent girls aged 10-19 years who were residing in the social and tribal welfare hostel in Kuppam mandal of Chittoor district, Andhra Pradesh, India.

Results: A total of 583 adolescent school girls were studied. There was a high prevalence of under nutrition (70.5\%), which was significantly associated with the early age. We also noted higher prevalence of morbidity conditions like reproductive $(28.7 \%)$, skin $(21.5 \%)$ and dental problems $(19.2 \%)$.

Conclusions: The outcome of this nutritional assessment among adolescent girls can be used as the basis for policymaking decisions at various ministry levels such as ministry of social welfare and ministry of women and child development. Ensuring regular school health programmes for health education, early detection and proper treatment will bring down the burden of malnutrition among these populations.
\end{abstract}

Keywords: Adolescence, Malnutrition, Anaemia, Hostels, Rural

\section{INTRODUCTION}

Adolescence period is very crucial since these are the formative years in the life of an individual when major physical, psychological and behavioural changes take place. Future of a society depends on adolescents and they form a great human resource for the society. Nutritional and health needs of the adolescents are also more because of more requirements for growth spurt and increase in physical activity. ${ }^{1}$ In 2009 , there were 1.2 billion adolescents aged 10-19 in the world, forming 18 per cent of world population. Adolescent numbers have more than doubled since 1950 . The vast majority of adolescents -88 per cent - live in developing countries. ${ }^{7}$ In India they constitute around 23 percent of the total population. $^{2}$

Adolescent girl's health covers nutritional status, morbidity, and reproductive health. Undernutrition, anaemia, infectious diseases and parasitic infections 
among adolescents are a serious public health problem internationally, especially in developing countries. The WHO report on adolescent nutrition states that hostels are having a considerable impact on their education and overall development. ${ }^{3}$ Under the constitution of India it is the responsibility of the government to safeguard the rights and privileges of the weaker sections of the society through various social welfare measures. ${ }^{4}$ In order to achieve the objective the Government of Andhra Pradesh has started a large number of social welfare hostels and at present, there are 2313 hostels functioning in the state with scheduled caste children comprising $70 \%$, of the hostel inmates. ${ }^{5}$

However very few studies have been conducted with regard to the nutritional status and morbidity conditions are sparse among the adolescent girls residing in social welfare hostels. Keeping this in view the present study was conducted to assess their nutritional status and to find out the associated morbidity conditions so that baseline data can be provided to the social welfare department in order to take up preventive and control activities will be implemented along with health educational programs for these group.

The study was done with the objectives of assessing the nutritional status and morbidity conditions among adolescent girls residing in a social welfare hostel and to study association between nutritional status and morbidity conditions among these adolescent girls.

\section{METHODS}

\section{Study setting and design}

A cross sectional study was conducted among adolescent girls aged 10-19 years who were residing in the social and tribal welfare hostel in the Paramasamudram village of Kuppam mandal of Chittoor district, Andhra Pradesh, from April to September 2015. A total of 583 adolescent girls were residing in the hostel studying in various classes from $5^{\text {th }}$ to intermediate. Hence all the adolescent girls present in the hostel at the time of study were included in the study. Permission from assistant social welfare officer and assistant tribal welfare officer was obtained for conducting the study and the wardens were intimated prior accordingly. The study was conducted as part of Indian Council of Medical Research (ICMR), Short Term Studentship (STS) project and the study was approved by the institutional ethics committee (IEC).

\section{Variables}

The data was collected with the help of a pre-tested proforma which included variables like sociodemographic profile, anthropometric measurements like height, weight, hemoglobin estimation by Sahli's method and clinical examination.

\section{Anthropometric metric measurements}

Height: For measuring height, stadiometer was used with an accuracy of $0.1 \mathrm{~cm}$. The study participants were made to stand without foot wear with the feet parallel and with heels, buttocks, shoulders, and occiput touching the measuring rod, hands hanging by the sides. The head held comfortably upright with the top the head making firm contact with the horizontal head piece.

Weight: A portable spring balance weighing machine with an accuracy of $100 \mathrm{gms}$ was used to record the weight of the girls. Checking the scale with a known weight was done frequently and adjustment to zero was done every time for accurate reading. Participants were instructed to stand on the weighing machine with light clothing and without footwear and with feet apart and looking straight and weight was recorded to the nearest value. Body mass index (BMI) - of the girls were classified into various grade based on BMI according to National standard undernutrition (BMI $<18.5 \mathrm{~kg} / \mathrm{m}^{2}$ ), Normal (BMI 18.5-23.5 kg/m²), and Overweight (BMI $\left.>23.5 \mathrm{~kg} / \mathrm{m}^{2}\right)^{5}$

Hemoglobin estimation: For hemoglobin estimation by Sahli's method a subsample of $20 \%$ was taken into consideration. ${ }^{6}$ Therefore 99 adolescent girls out of 495 were selected by applying systematic random sampling method. The sampling interval obtained was 5 (i.e. 495/99). After making complete list of all the study participants a random number was selected between one to five by lottery method as it will form the first study subject and subsequent samples were selected by cumulative addition of sampling interval so that hemoglobin estimation was done in a total of 99 adolescent girls. Free distribution of iron folic tablets and deworming will done if any of the study participant found to be anaemic and suffering from intestinal infestation. They will be referred to the urban health training center in case if they are found to be suffering from any morbidity condition. The collected data was analyzed by using proportions, percentages and chi-square test.

Clinical examination: For obvious signs of micronutrient deficiency i.e. Pallor/ Koilonychia / Thyroid enlargement / Glossitis / Cheilitis / Angular stomatitis / Aphthous ulcers.

\section{Statistical analysis}

The data was collected, compiled, and analyzed by using statistical package for social sciences (SPSS) version 19.0. Means, percentages and proportions were applied by univariate analysis and chi-square test was used to find out the association between age and nutritional status of the adolescent girls. 


\section{RESULTS}

A total of 583 adolescent school girls were studied. Details of age wise distribution of the girls is shown in Table 1. The age group 14 years contains highest $(20.6 \%)$ number of population and the age group 19 years contains the lowest number $(0.5 \%)$ population. About $15.4 \%$ girls are age group 13 years and $14.6 \%$ are age group 11 years. $13.9,12.9 .7 .7,7.2$ and $6.3 \%$ girls were $12,15,16,10$ and 17 years old respectively.

Table 1: Age wise distribution of adolescent school girls $(n=583)$.

\begin{tabular}{|lll|}
\hline Age (in years) & No. & Percentage (\%) \\
\hline 10 & 42 & 7.2 \\
\hline 11 & 85 & 14.6 \\
\hline 12 & 81 & 13.9 \\
\hline 13 & 90 & 15.4 \\
\hline 14 & 120 & 20.6 \\
\hline 15 & 75 & 12.9 \\
\hline 16 & 45 & 7.7 \\
\hline 17 & 37 & 6.3 \\
\hline 18 & 5 & 0.9 \\
\hline 19 & 3 & 0.5 \\
\hline Total & $\mathbf{5 8 3}$ & $\mathbf{1 0 0 . 0}$ \\
\hline
\end{tabular}

Majority $(86.3 \%)$ of the adolescent girls were Hindu by religion and more than one third of the subjects had three or more siblings in the family. With respect to parent's education, more than one third $(34.8 \%)$ mothers and $26.2 \%$ of fathers of adolescent girls were illiterate. Most of the fathers $(63.6 \%)$ and mothers $(60 \%)$ were educated upto high school. Almost half of the mothers were housewives and $6.7 \%$ of fathers of adolescent girls were unemployed as shown in Table 2. The mean weight, height and BMI were depicted in Table 3.

Table 4 shows that the morbidity status of the adolescent school girls residing in the social welfare hostel. About $28.8 \%$ of them were suffering reproductive problems either in the form of burning micturition, vaginal discharge, menorrhagia or pain during menstruation. $21.5 \%$ were having skin problems, $19.2 \%$ had dental problems, $12.9 \%$ were having signs of pallor and $8.2 \%$ of them had vitamin B complex deficiency. ENT problems, thyroid enlargement, history of passing worms in stools and URTI were noticed in $5.1 \%, 8.2 \%, 2.6 \%$ and $6 \%$ of adolescent girls.

Nutritional status of the adolescent girls according to body mass index (Table 5 and Figure 1) shows that of the $70.5 \%$ undernourished $37.2 \%$ were suffering from severe under-nutrition followed by mild (18.5\%) and moderate $(14.8 \%)$. The problem of overweight and obesity was noticed in $2.8 \%$ of the study population. Of the 62 adolescent girls in whom hemoglobin levels estimated a total of $46.8 \%$ were anaemic of which girls with moderate $(24.3 \%)$ and mild $(19.3 \%)$ were more when compared to severe anaemia (Table 6 and Figure 2).

Table 2: Distribution of sociodemographic variables of study subjects.

\begin{tabular}{|lll|}
\hline Variables & No. & Percentage (\%) \\
\hline Religion & & \\
Hindu & 503 & 86.3 \\
Muslim & 80 & 13.7 \\
\hline Siblings & & \\
Nil & 14 & 2.4 \\
One & 135 & 23.1 \\
Two & 204 & 35.0 \\
Three or more & 230 & 39.5 \\
\hline Father's education & & \\
Graduate & 26 & 4.5 \\
Inter & 33 & 5.7 \\
High school & 193 & 33.1 \\
Middle school & 118 & 20.2 \\
Primary & 60 & 10.3 \\
Illiterate & 153 & 26.2 \\
\hline Mother's education & & \\
Graduate & 6 & 1.0 \\
Inter & 24 & 4.1 \\
High school & 138 & 23.7 \\
Middle school & 143 & 24.5 \\
Primary & 69 & 11.8 \\
Illiterate & 203 & 34.8 \\
\hline Father's occupation & & \\
Profession & 7 & 1.2 \\
Semiprofession & 9 & 1.5 \\
Clerical & 206 & 35.3 \\
Skilled & 140 & 24.0 \\
Semiskilled & 94 & 16.1 \\
Unskilled & 88 & 15.1 \\
Unemployed & 39 & 6.7 \\
\hline Mother's occupation & & \\
Profession & 2 & 0.3 \\
Semi profession & 7 & 1.2 \\
Clerical & 115 & 19.7 \\
Skilled & 53 & 5.7 \\
Semiskilled & & 7.9 \\
Unskilled & 16.3 \\
Housewife & & \\
Total & & \\
\hline & & \\
& & \\
\hline
\end{tabular}

Table 3: Distribution of weight, height and body mass index of study participants.

\begin{tabular}{|ll|}
\hline Variables & Mean \pm SD \\
\hline BMI & $16.94 \pm 2.97$ \\
\hline Height $(\mathrm{cm})$ & $142.15 \pm 10.37$ \\
\hline Weight $(\mathrm{Kg})$ & $34.90 \pm 9.02$ \\
\hline
\end{tabular}

Majority i.e. $78.7 \%$ of adolescent girls belongs to the age group of $10-14$ years are undernourished. Similarly $57.9 \%$ of adolescent girls belongs to the age group of 15 19 years are under nourished with $\mathrm{X}^{2}=23.4$ and $\mathrm{P}$ value 
$=<0.0001$ showing highly significant association between age of participants and body mass index (Table 7).

Table 4: Details of morbidity conditions among study subjects.

\begin{tabular}{|lll|}
\hline Indicators & No. & Percentage (\%) \\
\hline Dental problems & 112 & 19.2 \\
\hline Vit B complex deficiency & 48 & 8.2 \\
\hline Thyroid enlargement & 24 & 4.1 \\
\hline Skin problem & 09 & 21.5 \\
\hline ENT problem & 30 & 5.1 \\
\hline Clinical anaemia & 75 & 12.9 \\
\hline Passing worms in stools & 15 & 2.6 \\
\hline Pediculosis & 12 & 2.1 \\
\hline URTI & 35 & 6 \\
\hline h/o RTI & 168 & 28.8 \\
\hline
\end{tabular}

Table 5: Nutritional status of study population as per national classification according to BMI. $^{6}$

\begin{tabular}{|lcl|}
\hline BMI & No. & $\begin{array}{l}\text { Percentage } \\
(\%)\end{array}$ \\
\hline Severe under-nutrition $(<16)$ & 217 & 37.2 \\
\hline Moderate under-nutrition $(16-16.9)$ & 86 & 14.8 \\
\hline Mild under-nutrition $(17-18.49)$ & 108 & 18.5 \\
\hline Normal (18.5-22.9) & 157 & 26.9 \\
\hline Overweight $(23-27.5)$ & 14 & 2.6 \\
\hline Obese $>27.5$ & 1 & 0.2 \\
\hline Total & $\mathbf{5 8 3}$ & $\mathbf{1 0 0}$ \\
\hline
\end{tabular}

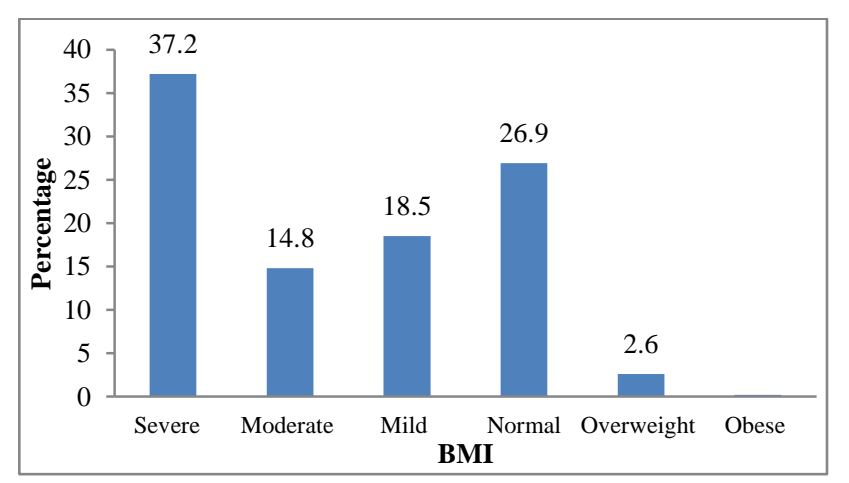

Figure 1: Nutritional status of adolescent girls according BMI.

Table 6: Distribution of adolescent girls according to hemoglobin content $(n=62)$.

\begin{tabular}{|lcl|}
\hline Hemoglobin level & No. & Percentage $(\%)$ \\
\hline Normal & 33 & 53.2 \\
\hline Mild anaemia & 12 & 19.3 \\
\hline Moderate anaemia & 15 & 24.3 \\
\hline Severe anaemia & 2 & 3.2 \\
\hline Total & $\mathbf{6 2}$ & $\mathbf{1 0 0}$ \\
\hline
\end{tabular}

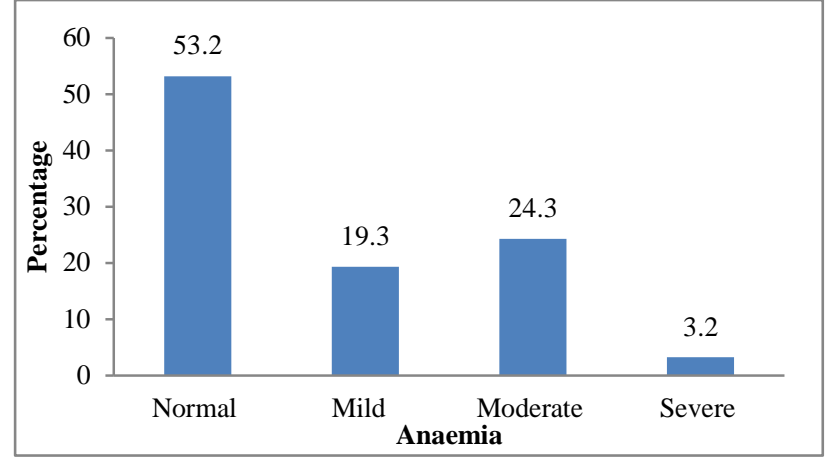

Figure 2: Distribution of anaemia among adolescent girls $(n=62)$.

Table 7: Association of nutritional status with age $(\mathbf{n}=\mathbf{5 7 8} *)$.

\begin{tabular}{|lll|l|}
\hline \multirow{2}{*}{ Age group } & \multicolumn{2}{c|}{ BMI } & \multirow{2}{*}{ Total } \\
\cline { 2 - 3 } & Undernourished & Normal & \\
\hline $10-14$ & $326(78.7 \%)$ & $88(21.3 \%)$ & 414 \\
\hline $15-19$ & $95(57.9 \%)$ & $69(42.1 \%)$ & 164 \\
\hline Total & $\mathbf{4 2 1}(\mathbf{7 2 . 8 \%})$ & $\mathbf{1 5 7}(\mathbf{2 8 . 2 \%})$ & $\mathbf{5 7 8}$ \\
\hline
\end{tabular}

(*Overweight and obese were excluded); $\mathrm{X}^{2}=25.7$ and $\mathrm{P}$ value $=<0.0001$ ).

\section{DISCUSSION}

Adolescence is a time of increased nutritional requirements. Due to the high velocity of growth, adolescents have some of the highest energy and protein requirements of any age group. In the present study $70.5 \%$ of adolescent school girls were undernourished. The findings were similar to the studies done by Joshi SM, Goyle A and Shivaramakrishna et al in which the prevalence of undernutrition was $69 \%, 72 \%$ and $73.5 \%$ respectively. ${ }^{7-9}$ High prevalence was probably due to most of the adolescent girls were from rural areas and belonging to poor socioeconomic status.

Majority of under nourished adolescent girls i.e. $78.7 \%$ belongs to the age group of 10- 14 years, followed by $57.9 \%$ of adolescent girls of 15-19 years. Thus indicating a strong association between nutritional requirements in early adolescence period. National nutrition monitoring bureau reported that under-nutrition decreased from $78 \%$ in $10-13$ years to $66 \%$ in $14-17$ years. ${ }^{10}$ Similar findings were reported by Joshi SM. ${ }^{7}$ The reason could be because of the early growth spurt seen in the girls with sudden increase in height in early age group.

With respect to morbidity conditions there was a high prevalence of skin problems $(21.5 \%)$ was noted in our study which is similar to a study Gupta KB (23.2\%) as well as Srinivasan K (25.7\%). ${ }^{6,11}$ The prevalence of dental caries in the present study $(19.2 \%)$ is comparable to the findings by Chabbra $\mathrm{P}(16.1 \%){ }^{12} 28.7 \%$ of girls had reproductive problems in the form of burning micturition, vaginal discharge and pain during menstruation which 
was similar to findings by Wasnik V (16.7\%). ${ }^{5}$ High prevalence of above morbidity conditions might be due to may be due to poor personal hygiene, lack of awareness regarding common diseases and overcrowding. The present study has revealed the prevalence of ARI as $6 \%$ while Chopdar A reported a higher prevalence of $7.1 \% .^{13}$

The prevalence of anaemia in the present study was $46.8 \%$ which was lower than reported by Padmaja $\mathrm{P}$ $(68 \%)$ and by Seshadri S $(60 \%))^{14,15}$ Hemoglobin estimation was done only in subsample of study subjects and this might be the reason for lower figures compared to other studies as mentioned.

\section{CONCLUSION}

Assessing the nutritional and morbidity status among adolescent girls who are staying in social welfare hostels who are generally from the marginalized section of the society will throw a light on the conditions influencing malnutrition among adolescent girls. In our study there was higher prevalence of under-nutrition and it was significantly associated with early years of adolescence period. There was also high prevalence of morbidity conditions. Training of school health personnel for regular periodic medical examination and facilities for treatment on the spot at school hostels and referral services should be organized and monitored systematically further research like in depth analysis of micronutrient deficiencies, issues concerned to menstrual hygiene and dysmenorrhea can be carried out based on the study findings. The outcome of this nutritional assessment among adolescent girls can be used as the basis for policy-making decisions at various ministry levels such as Ministry of Social Welfare and Ministry of Women and Child Development.

Funding: No funding sources Conflict of interest: None declared

Ethical approval: The study was approved by the Institutional Ethics Committee

\section{REFERENCES}

1. Kishore J. National Health Programs of India. 11th Ed. New Delhi: Century: 2014. Chapter 8, Reproductive And Child Health Program-II; p.202203.

2. Park K. Textbook of Preventive And Social Medicine. Chapter 10, Preventive Medicine in Obstetrics, Paediatrics and Geriatrics, $22^{\text {nd }}$ ed. Jabalpur: Banarsidas Bhanot; 2013: 548-549.

3. WHO. Adolescent Nutrition: A Review of the Situation in Selected South-East Asian Countries, 2006. Available from http:// www.searo.who.int/ entity/ child_adolescent/ documents/ sea_nut_163/en/ (Accessed on 30-05-2015).

4. Sharada R, Damayanthi MN, Vidya B, Shashikala M. Nutritional Status of Children Residing In Social Welfare Hostel in Bangalore City. Annals Commu Healt . 2014;2(2):31-4.

5. Wasnik V, Rao BS, Rao D. A Study of the Health Status of Early adolescent Girls Residing in Social Welfare Hostels in Vizianagaram district of Andhra Pradesh State, India. Intl J Col Res Int Med \& Pub Health. 2012;4(1):72-83.

6. Srinivasan K, Prabhu GR. Study of Morbidity Status of Chilren in Social Welfare Hostels in Tirupati Town. Indian J Com Med. 2006;31(3):170-2.

7. Joshi SM, Likha S, Agarwal SS, Mishra M K, Shukla U. Nutritional Status of Adolescent Girls in Rural area of Bhopal District. Natl J Com Med. 2014;5(2):191-4.

8. Goyle A. Nutritional status of girls studying in a government school in Jaipur city as determined by anthropometry. Anthropologist. 2009;11: 225-7.

9. Shivaramakrishna HR, Deepa AV, Sarithareddy M. Nutritional Status of Adolescent Girls in Rural Area of Kolar District -A Cross-Sectional Study. Al Ameen J Med Sci. 2011;4(3):243-6.

10. National Nutrition Monitoring Bureau. Diet and nutritional status of rural population, Hyderabad: National institute of Nutrition, Indian Council of MedicalResearch;2002. p91.

11. Gupta KB, Walia BN. A longitudinal study of morbidity in children in a rural area of Punjab. Indian J Pediatr. 1980;47(387):297-301.

12. Chabbra P, Garg S, Sharma N, Bansal RD. Health and Nutritional status of boys aged 6-12 years in a children's observation home. Indian J Public Health. 1996;40(4):126-9.

13. Chopdar A, Mishra PK. Health status of rural schoolchildren in Western Orissa. Indian J Pediatr. 1980;47:203-6.

14. Padmaja PA, Lakshmi AV, Mahatab SB. Riboflavin and Haemoglobin status of Urban school boys: relationship with income, diet and anthropometry. Indian J Pediatr. 1987;54(4):529-33.

15. Seshadri S. Weekly implementation of iron in rural adolescent girls In: Malnutrition in South Asia-A regional profile, 1996, ROSA publications, S, 79. 9. Taneja MK, Sandel J, Shukla PL. Health status of urban school children in Western Uttar Pradesh. Indian J Pediatr. 1978;45;359-63.

Cite this article as: Udayar SE, Kommula D, Prasad DV. Study of nutritional status and its relation to morbid conditions among adolescent girls residing in social welfare hostels in the Kuppam mandal of Chittoor district, Andhra Pradesh, India. Int J Community Med Public Health 2016;3:636-40. 